\title{
LA PRIMERA FORTALEZA Y MUELLE DE SANTA CRUZ DE TENERIFE. LA EVOLUCIÓN DEL LUGAR Y PUERTO EN EL SEGUNDO TERCIO DEL SIGLO XVI (I)
}

\author{
Alberto García Montes de Oca* \\ José Miguel Rodríguez Illescas**
}

\section{RESUMEN}

El puerto de Santa Cruz es la razón de ser de este lugar, villa y ciudad tinerfeńa desde su fundación. Ha sido y sigue siendo un centro neurálgico de tránsito de mercancías y de personas, y ha jugado un papel fundamental en la actividad diplomática oceánica castellana y española desde su fundación. Ha sido fundamental para la ciudad de San Cristóbal, la Isla y la Corona castellana desde su constitución, y, desde poco después, destaca de igual manera en el ámbito de influencia internacional. Ha sido vital para el desarrollo de la economía y sociedad del Archipiélago Canario y base estratégica en la Carrera de Indias. La ubicación del puerto de Santa Cruz bajomedieval y moderno, estudiada desde diversos puntos de vista, ha sido muy variada, pero no interpretada correctamente del todo.

Palabras Clave: Santa Cruz de Tenerife, puerto, muelle, fortaleza, siglos XVI y XviI, método arqueológico, naufragios.

\section{THE FIRST FORT AND DOCK OF SANTA CRUZ DE TENERIFE. THE EVOLUTION OF THE PLACE AND HARBOUR IN THE SECOND THIRD OF XVI ${ }^{\mathrm{TH}}$ CENTURY (I)}

\section{Abstract}

Santa Cruz harbour is the soul of this place, village and city of Tenerife since its foundation. It has been and keep being a main core of trade and people transit, and have played an essential role in the Castillian and Spanish oceanic diplomacy since its origin. The harbour, has been essential for he city of San Cristóbal, the Island and the Castillian Crown since its constitution, and since short time after, in the international influence area. The harbour of Santa Cruz have been vital for the Canarian Archipelago economical developement, and an essential base in the Indian Spanish Race. The placement of the harbour of the Low Medieval and Modern Santa Cruz, studied from different points of view, has been very variety, but it has not almost been correctly interpreted.

Keywords: Santa Cruz de Tenerife, harbour, dock, fort, Xvi and Xvir Centuries, archaeological method, shipwrecks. 


\section{INTRODUCCIÓN}

Los autores de este artículo investigamos el desarrollo de los núcleos urbanos de Tenerife en el marco del proyecto Carta Arqueológica Subacuática de Tenerife. Debido a que no se puede entender nuestro panorama urbano actual sin conocer el origen y desarrollo de la ciudad, consideramos que lo más oportuno para asentar las bases del trazado urbano actual de Santa Cruz es acudir a las fuentes documentales originales, teniendo en cuenta interpretaciones posteriores a las mismas y previas a nuestro presente. Las interpretaciones previas han sido comparadas, contrastadas y confrontadas con muchos documentos originales, además de estudiar documentos no analizados anteriormente. Es nuestra grata labor ofrecer a quien lea este estudio científico el acceso digital a los documentos originales de los que salen dichos datos ${ }^{1}$.

Existen numerosas fuentes estudiadas y reinterpretadas, destacando la documentación original del Archivo Municipal de La Laguna: actas del Cabildo, notas sobre las actas del Cabildo, reales cédulas e informes sobre fábricas públicas y fortificaciones, sin olvidar la importantísima información registrada en el protocolo notarial de Francisco de Zambrana, entre los años 1565 y 1569, que transcribimos los autores en 2018. Desgraciadamente, los protocolos notariales de la década anterior y posterior a 1565 están bastante deteriorados, de modo que no hemos podido analizarlos todavía.

Para entender los documentos escritos, la cartografía y los planos son esenciales para la interpretación visual, sin olvidar que la traza original de la costa muy poco se asemeja a la actual. Entre la refinería y San Andrés no quedan sino unos 100 metros del litoral original intactos, algo de lo que la ciudadanía muchas veces no se percata. Lo que mostramos parte de un amplio abanico de cuestiones y fuentes analizadas, no solo los documentos escritos. Entre otros aspectos, la lógica urbanística de un lugar va siempre vinculada al estudio geomorfológico del mismo, y a las dinámicas erosivas y sedimentarias de su entorno.

Nos centraremos en ofrecer un discurso sobre la evolución de la actual capital tinerfeña en el periodo señalado de forma acotada, sintética, y siempre basándonos en documentos originales, en bibliografía ya escrita y en la reinterpretación lógica de la evolución del lugar, valiéndonos de conocimientos sobre orografía, geosedimentación, urbanismo, cartografía, clima, navegación, arqueología e historia, todo ello marcado por el factor tiempo.

* Historiador, arqueólogo especialista en prospección arqueológica subacuática, director del proyecto Carta Arqueológica Subacuática de Tenerife, vicepresidente de SONARS-Asociación Nacional de Arqueología Subacuática, director de la sección de Patrimonio Cultural Sumergido de FEDECAS. E-mail: albertogmdo@gmail.com.

** Historiador especialista en historia militar y en la Marina de guerra en el periodo de entreguerras del siglo xx, investigador en el proyecto Carta Arqueológica Subacuática de Tenerife. E-mail: jomirocasa@msn.com.

${ }^{1}$ Serán colgados en la web https://www.facebook.com/sonars.arqueologia/. 


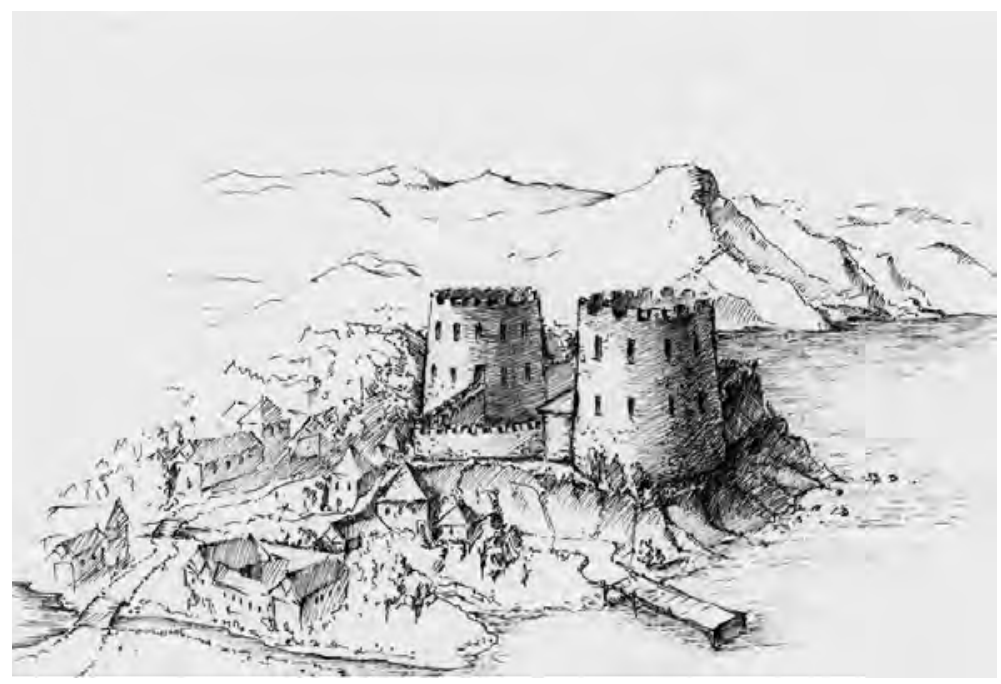

Figura 1. Boceto de la vista ideal de Santa Cruz en torno a 1560, destacando la fortaleza. Autora: Elena Vladimirovna Pochepkina.

De todas las imágenes viene señalada su fuente principal y autoría, pero han sido compuestas y desarrolladas por Alberto García Montes de Oca.

\section{BASES PARA LA FUNDACIÓN}

En primer lugar, nos situaremos en el Santa Cruz de 1494, año de su fundación; sin olvidar que décadas antes Sancho de Herrera había asentado en el lugar una torre defensiva, en el que posiblemente fuera el emplazamiento de una de las puntas de lanza de la traza italiana del Castillo de San Cristóbal, aunque este hecho no ha sido verificado ni desmentido todavía. La referencia a la ubicación de la torre primigenia, en el barranco de Ańazo, se sucede en el relato de Espinosa (Espinosa, 1591, Libro III: 64r-65v) a los acuerdos del barranco del Bufadero. Atribuimos esta localización al actual Bufadero, al que iba asociado un fondeadero que podría aludir a cualquier formación basáltica sólida del entorno, lindante con el mar, y con oquedades que hiciesen posible que el mar, al chocar con la roca, presurizase el agua en forma del chorro conocido como bufadero ${ }^{2}$. Sobre la torre, debemos tener en

2 Explicación dada por Sebastiana Montesdeoca Mendoza, a quien le agradecemos enormemente sus aportes. In memoriam. 
cuenta su deducible cercanía al mar, en un entorno próximo al fondeadero, y, posiblemente, su reaprovechamiento en décadas posteriores ${ }^{3}$.

En cualquier caso, hasta no tener una fuente documental escrita o arqueológica sólida, no podemos dictaminar unos hechos no contrastados, ya que muchos documentos se han perdido o diseminado. Pero para el momento en el que se fundó Santa Cruz, sí podemos establecer una serie de parámetros:

El lugar fundacional de Santa Cruz está ubicado al sur de una rada. En un primer momento, el interés de los castellanos es asentarse en un lugar defendible, tanto de las poblaciones indígenas como de los atacantes externos. El lugar más propicio, por poseer agua de escorrentía, agua freática dulce y salobre ${ }^{4}$, estar en un entorno de relativa fácil defensa y desde donde se podía ejercer un claro dominio sobre el territorio y el mar, era la franja de basalto que estaba entre el barranco de Añazo y la actual plaza de la Candelaria. Sobre muchas de sus secciones, las construcciones podían ser robustas, pesadas y sólidas. Además, la colada basáltica que bajaba hasta el mar estaba seccionada por un barranco de estrechas dimensiones conocido como barranquillo del Aceite, en cuya desembocadura, al sur de la lengua de roca que más se adentraba en el mar y colindante con ella, se formaba una playa, seguramente de arena y clastos de mayor tamaño traídos por la escorrentía del barranco -que, por sus dimensiones, no arrastraría cantos demasiado pesados-. En esta playa vararían las embarcaciones locales y no se descartan actividades de carpintería de ribera.

\section{GEOGRAFÍA Y CLIMA DEL ENTORNO DE SANTA CRUZ}

Santa Cruz se encuentra en un entorno basáltico de datación cuaternaria de la serie III orogénica ${ }^{6}$, que, a grandes rasgos, cubre la superficie que se encuentra entre el macizo de Anaga y el inicio de la cordillera de La Esperanza, extendiéndose hacia el noroeste y el sureste. Al norte, cuenta con la protección del macizo de Anaga, la parte geológicamente más antigua de la Isla, una serie de montañas, con numerosos barrancos que horadan la cordillera. Las áreas litorales próximas a las desembocaduras de estos barrancos están compuestas por arenas y limos, además de otros clastos, que, por lo general, hacen de la pronunciada orografía subacuática de la Isla un entorno con un gradiente de desnivel más suave. La Isla, cuyo complejo basal se erige desde las profundidades oceánicas, se eleva de forma pro-

${ }^{3}$ La teoría fue estudiada en el proyecto sobre los 25 primeros años de Santa Cruz, dirigido por Carlos Pallés, donde colaboramos como historiadores y arqueólogo, respectivamente.

${ }^{4}$ Vital para evitar la corrupción del agua el mayor tiempo posible.

5 Actual barranco de Santos o de las Carnicerías.

${ }^{6}$ Mapa geológico de Espańa 1: 50 000, Santa Cruz de Tenerife, n. ${ }^{\circ} 1104-1105$, en http:// info.igme.es/cartografiadigital/datos/Geo50/memorias/d11_PS50/Memoria1105_PS50.pdf y http:// info.igme.es/cartografiadigital/datos/magna50/jpgs/d11_G50/Editado_MAGNA50_1104IA.jpg. 
nunciada desde el lecho oceánico 7 . Debido a este destacado gradiente originado por su origen volcánico, el perfil litoral subacuático es muy pronunciado, salvo en los entornos donde se depositan los flujos sedimentarios de las escorrentías aluviales, sobre todo, en las partes geológicamente más antiguas de la Isla, donde se generará una batimetría más suave y con extensas áreas donde el fondeo puede ser más plausible. En otras palabras, los entornos de las desembocaduras de los barrancos suelen ser extensiones de arena y clastos, donde el fondeo es más cómodo y sin profundidades extremas. Por otra parte, estos entornos sedimentarios propician una mejor conservación del material arqueológico que en ellos se deposite, ya que los mismos sedimentos ofrecen una eficaz cobertura a los materiales depositados. Hoy en día, hay muchos restos bajo el hormigón, construcciones e infraestructuras portuarias y litorales, que en ocasiones han sido destruidos conscientemente, aunque en este escrito no nos extenderemos relatándolo.

En relación con la geografía y la dinámica sedimentaria, el clima de las Islas es fundamental para entender su poblamiento y la disposición de los entornos portuarios a lo largo de su litoral, siempre en relación con la navegación. Las Islas Canarias, y en este caso Tenerife, se encuentran en la parte suroriental del Atlántico Norte, al oeste del Sáhara Occidental, en un entorno subtropical árido y no desierto, ya que las corrientes oceánicas del Atlántico Norte, que circulan en sentido horario a lo largo y ancho de dicho océano en el hemisferio norte, brindan con el Alisio -viento de componente norte- la humedad oceánica, que queda retenida en sus montañas en forma de nubes, lo que aporta precipitación y precipitación horizontal ${ }^{8}$. El alisio, presente durante todo el año, asociado a la dinámica de corrientes marinas superficiales, en ocasiones, sobre todo entre octubre y marzo, se complementa o modifica por vientos generalmente del suroeste, componentes eólicos principales de las borrascas de los meses fríos, y de aporte húmedo desde el sur, más cálido en estos periodos. Por lo tanto, en el área que estamos analizando, en la vertiente suroriental del norte de Tenerife, predominará el alisio, así como, generalmente, borrascas del suroeste en los meses fríos. Como la dinámica climática principal será regida por el alisio y sus variantes nororientales y noroccidentales, Santa Cruz, a grandes rasgos, queda protegida de las principales inclemencias del tiempo.

El lugar en el que se ubica es propicio, ya que se trata de una bahía bajo la cobertura del macizo de Anaga, al resguardo de los vientos predominantes, relativamente cerca de la capital de la Isla, San Cristóbal, a la que se accedía por caminos mucho menos empinados que los que circulaban por las montańas de dicho macizo. El lugar de Santa Cruz estaba situado específicamente en una colada basáltica, con áreas de deposición sedimentaria, y en las proximidades de entornos sedimentarios

${ }^{7}$ http://www.ign.es/resources/docs/IGNCnig/VLC-Teoria-Volcanologia.pdf.

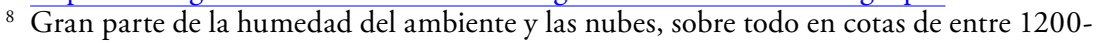
1500 metros, queda retenida en el terreno por contacto y saturación, y por la vegetación. Gran parte de esta agua pasa a engrosar el nivel freático. 


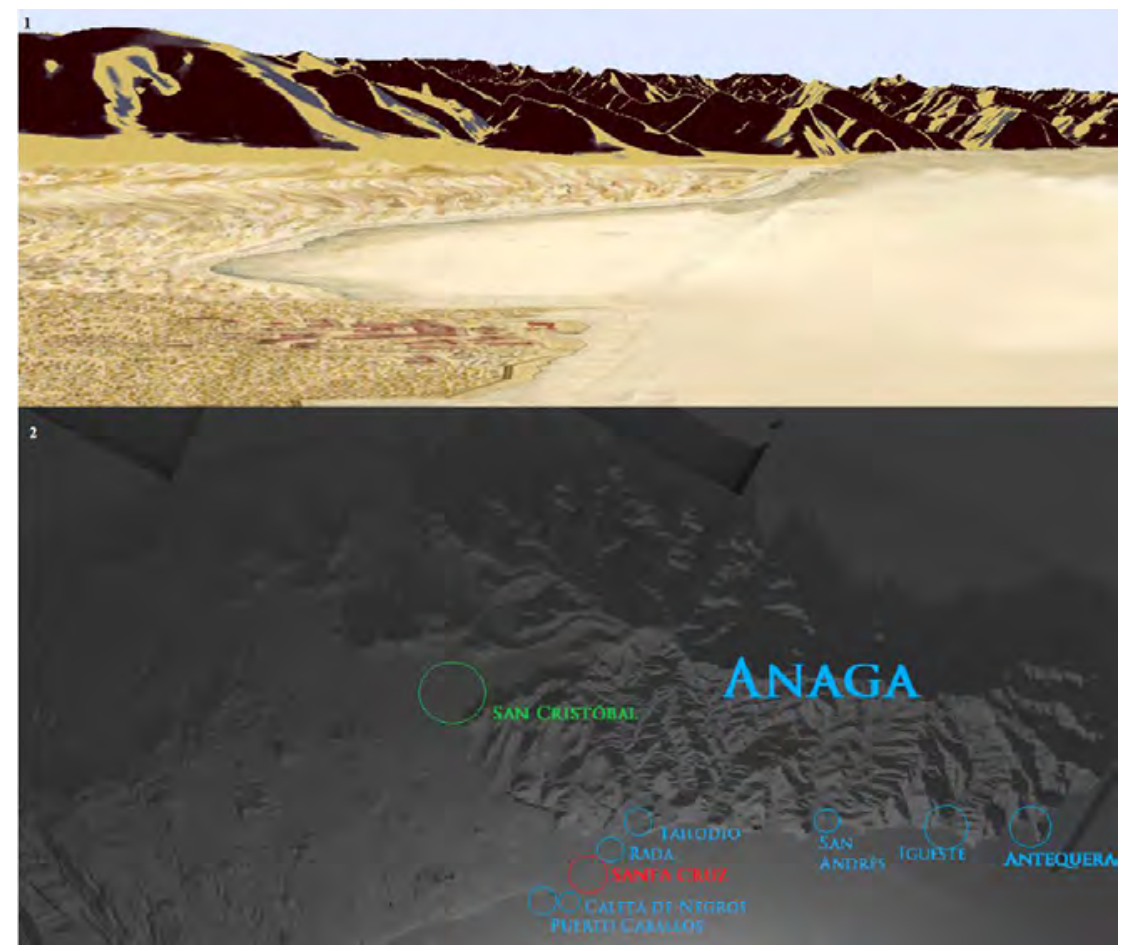

Figura 2. 1, Perspectiva del lugar de Santa Cruz de Tenerife y su entorno desde el sur hacia el norte, partiendo del plano de Torriani de 1589, modificando su orientación, sus edificaciones y leyendas, y manteniendo las proporciones de la perspectiva, aunque no su relación de aspecto, levantando en el fondo, desde la misma perspectiva, un MDT del macizo de Anaga. 2. Vista en planta del extremo nororiental de Tenerife, con indicación de la ciudad y los principales fondeaderos de Santa Cruz y su litoral nororiental.

y entornos costeros, que permitían el cultivo y el acceso al mar, con la particularidad de que estos accesos eran también relativamente fácilmente defendibles.

Al lugar y puerto de Santa Cruz se accedía por vía marítima desde el nornoreste, costeando el litoral de Anaga, y antes de llegar a la rada de Santa Cruz, la costa ofrecía al menos tres fondeaderos relevantes: Antequera, primer resguardo que brindaba la Isla, el valle de Igueste, caserío en torno al barranco del mismo nombre en el que se cultivaba azúcar, y el valle de San Andrés o de Salazar, fondeadero al pie de un valle agrícola. Hacia el lugar y puerto, encontrábanse pequeños fondeaderos asociados a las desembocaduras de los barrancos que bajaban desde la cumbre, y a la entrada de la rada desde el norte, la extensión subacuática de la desembocadura del barranco de Tahodio habilitaba una gran área para el fondeo. Éste era plausible en toda la rada inmediata al norte del lugar, al igual que hacia el sur, hacia Caleta de Negros y Puerto Caballos, ubicado este último en la desembocadura del 
barranco Hondo, hoy conocido como barranco del Hierro9', colmatado en la actualidad por la montańa del Lazareto o Palmetum. Por su parte, el fondeadero principal de Santa Cruz durante el siglo XVI, al igual que durante gran parte del siglo XVII, era el entorno próximo a la mencionada colada de lava, con un fondo arenoso y de clastos de una textura ${ }^{10}$ no muy grande. La disposición de los sedimentos de granulometría fina era aportada por los diversos barrancos del entorno, de dimensiones reducidas, como el barranquillo del Aceite, junto a cuya desembocadura se erigía el muelle, o el barranco de San Francisco y el de San Antonio, al norte, cuyos sedimentos de escorrentías eran en parte desplazados hacia el lugar por las corrientes oceánicas. Por su parte, el fondeo próximo al barranco de Santos era más difícil, incluso peligroso, ya que a su desembocadura llegaban rocas de gran tamańo arrastradas por las avenidas aluviales, además de que, por las potentes escorrentías, podría ser peligroso fondear ahí. Sobre las lenguas de la colada basáltica, se construirían las defensas del puerto: baluarte, fortaleza y, al norte, el Castillo de San Cristóbal, por lo que la seguridad de los barcos fondeados ante agentes antrópicos ${ }^{11}$ se encontraba bajo la cobertura de los fuegos de los edificios mencionados.

\section{EL LUGAR Y PUERTO DE SANTA CRUZ DE TENERIFE}

Sobre este tema ya se ha escrito. Podemos ver descripciones y estudios en los trabajos de Rumeu de Armas o Cioranescu, mas aquí daremos una visión más ajustada, cercana y personal de lo que a la disposición de los edificios y espacios del lugar, durante el periodo señalado anteriormente, se refiere.

Partiendo de las trazas urbanas, defensivas y geográficas de la obra de Leonardo Torriani, extrapolaremos los datos plasmados en la documentación escrita y los ajustaremos a su plano de Santa Cruz de 1589, seńalando las modificaciones pertinentes, ya que las fechas en las que nos centraremos serán previas, cuando no se había construido aún el Castillo de San Cristóbal.

En primer lugar, hemos de aclarar que el plano de Torriani de Santa Cruz presenta una peculiaridad, que puede ser inherente a su formación como ingeniero: la línea de deslinde marítimo-terrestre está ubicada en el punto más bajo de las mareas muertas, tal y como se señalan las líneas de costa en las cartas náuticas, para que así se pueda disponer con seguridad de la información sobre el puerto, sorteando bajíos o salientes de roca. Un claro ejemplo lo podemos ver en la cartografía comparada del plano de Santa Cruz de Torriani y el plano del Castillo de San Cristóbal, del conjunto Castillo y Baterías de Tenerife, de $1728^{12}$, prestando especial aten-

\footnotetext{
9 Referenciado así en el mapa topográfico integrado del visor Idecanarias Grafcan. Esta nota aclaratoria especifica que no se denomina oficialmente barranco de El Hierro.

${ }_{10}$ Tamaño granular de los sedimentos.

${ }_{11}$ Atacantes e invasores.

12 En Biblioteca Virtual de Defensa, Castillo y Baterías de Tenerife, Carpeta 39, Plano 403 , pp. 7 y 8.
} 


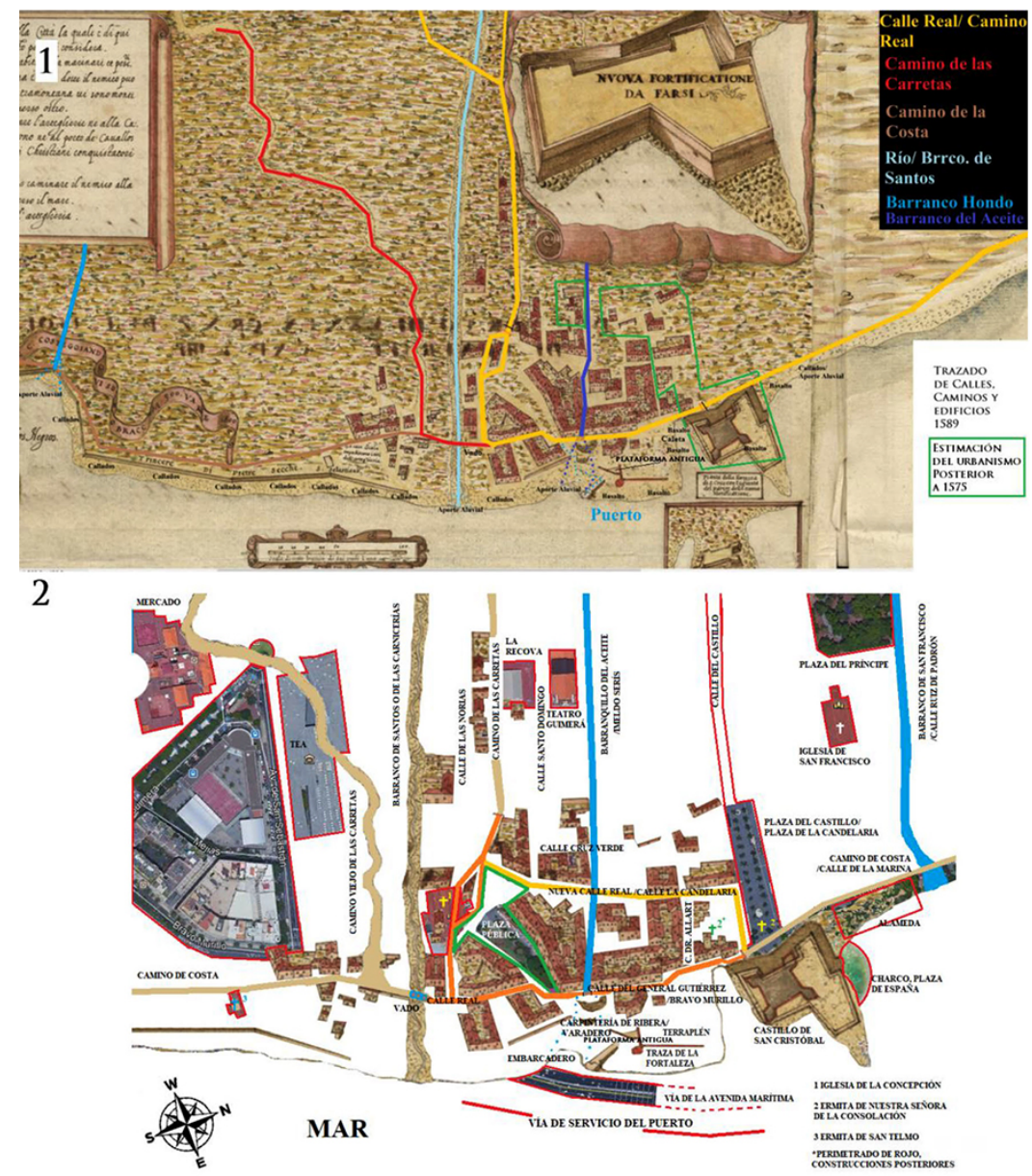

Figura 3. 1. Plano parcial de Santa Cruz de Leonardo Torriani, indicación de las características de su litoral, accidentes geográficos y trazado urbano. 2. Superposición del plano de Torriani con construcciones de la ciudad del siglo XXI, ajustándose su ubicación espacial. La imagen edilicia del siglo xxi proviene de Google Earth.

ción a la ubicación del muelle y la traza de los restos murarios de la fortaleza ${ }^{13}$ en el plano de Torriani, y en ambos documentos, prestando atención a la colada basáltica donde se ubicaba el Castillo de San Cristóbal, sobre la que dicho ingeniero proponía ensancharlo, y farallón que se aprovechó para construir el muelle de cabeza

${ }^{13}$ En cuyo cubelo sur batía la mar. 
de martillo, erigido bien entrada la segunda mitad del siglo XviII. Si bien aparece como lengua de terreno que se adentra en el mar en el plano del ingeniero cremonés, en los planos del siglo XVIII, vemos que, de esta formación, no salen del agua sino algunos picos y rocas.

Por otra parte, no hemos de olvidar, ya que nunca se dice o no se reconoce, que el espacio, terraplén y restos de la antigua fortaleza de Santa Cruz se reutilizan en el siglo XviI para levantar la batería de la Concepción, que, posteriormente, entre ambas fuerzas, protegerían la caleta de desembarco de la Aduana, a la que se asociaba dicho edificio, y por donde se desembarcaban las mercancías durante gran parte del siglo XVII y gran parte del siglo XVIII.

\section{Historia DE LA FORTALEZA Y EL MUELle}

Antes de explicar cómo se desarrolló la edificación de la fortaleza y del muelle, citaremos unas nociones básicas sobre su pasado y sobre los intentos y la construcción de sistemas defensivos rudimentarios antes de que se llegasen a finiquitar. Para ello, hemos acudido a todas las entradas que citan ambas construcciones en las actas del Cabildo publicadas ${ }^{14}$. Daremos un sucinto resumen de los textos analizados: Entre 1508 y 1510, en los juicios que se le hacen al adelantado, diversos testimonios mencionan los motivos por los que no se había hecho la torre que el puerto precisaba para su defensa $a^{15}$.

En enero de 1513, se determina que no hay fondos para construir la torre, y en junio de ese año se promueve la construcción de un baluarte, que se hiciere de forma que se pudiere anexar la torre a éste, si se construía en un futuro. En agosto,

${ }^{14}$ En ninguna de las referencias de las actas, ni en otros documentos analizados, se menciona que se construyese una torre o fortificación en 1511. La única torre que al parecer asentó Fernández de Lugo fue la de su campamento, donde quedó una guarnición tras su derrota en Acentejo en 1494, 28 días después de la fundación de Santa Cruz (Espinosa, Libro III: 80v-83v). Aunque se incentiva varias veces su construcción, no se desarrolla por falta de medios, por lo que Rumeu de Armas yerra en su afirmación, citando que, en 1511, el adelantado Alonso de Lugo hizo una torre, cuyo alcaide sería Juan de Benavente, y sus herederos Antón Joven y Juan de Ayala, que darían dicho derecho en la forma contractual de censo enfitéutico a Salvador Álvarez. Esta referencia se encuentra en el tomo i de Canarias y el Atlántico. Piratería y Ataques Navales contra las Islas Canarias, página 65. A su vez, no acompaña su afirmación de bibliografía alguna. Podemos determinar, por los textos de las actas, que en 1499, Juan de Benavente es alguacil mayor, y que fue también guarda del puerto, pero no alcaide. En julio de 1516, se nombra como teniente de alguacil, y el 15 de septiembre se menciona como alcaide, mas la referencia del índice lo determina como alcalde. Estas referencias se encuentran en los acuerdos del Cabildo, en los rangos de fechas señalados. Por motivos del confinamiento del presente 2020, no ha sido posible comprobar los textos originales, por lo que esta referencia quedará explicada en una nota a pie de página en la segunda parte del artículo.

${ }^{15}$ Las transcripciones de los juicios están en los apéndices documentales de la publicación de las actas del Cabildo de Tenerife iv. Apéndice II, 1. 
ya estaba construido el baluarte, una albarrada con una plataforma terraplenada, pero se requería fabricar un pretil almenado para cubrir a los defensores ${ }^{16}$.

En agosto de 1514 se intenta promover de nuevo la construcción de una torre, y en junio de 1515 se envía un mensajero a la Corte, para, entre otras peticiones, solicitar fondos para la construcción de dos torres, una en Garachico y otra en Santa Cruz.

En enero de 1522, se vuelve a planear una fortaleza, que no se hace. Y en mayo de 1524, se reclama de nuevo una torre.

Por otra parte, en octubre de 1525, se acuerda en una sesión del Cabildo pedir al rey medios para construir un muelle, pero finalmente éste no se construye.

\section{Segundo Tercio Del Siglo XVI}

Respecto al legajo de actas de entre 1533 y 1538, desconocemos qué pudo contener, pues ya figuraba como desaparecido en el siglo XVII ${ }^{17}$. Por ello, intentaremos encajar las secuencias lógicas que se debieron seguir:

Deducimos lógicamente que no había nada nuevo bajo el sol en cuestión de fortificaciones en Santa Cruz, ya que se denuncia en julio de 1543 que el baluarte y sus troneras están desbaratados. Quizás se levantase algún tipo de parapeto además de los pretiles y albarrada, pero, sin documentos que lo respalden, aún no podemos determinar nada. Ante posibles ataques a Santa Cruz, se manda a reparar.

En noviembre de 1543, se vuelve a hablar sobre lo mal defendidas que están las Islas. La motivación principal para la fortificación, al igual que en sendas ocasiones en los dos primeros tercios del siglo XVI, fueron las guerras entre Carlos I y Francisco I de Francia, conflictos que moverían a corsarios ${ }^{18}$ franceses hacia las costas bajo el dominio de las coronas hispánicas, especialmente en ultramar. Se denuncia la falta de torres en los puertos de Garachico, La Orotava y Santa Cruz, y se platica a su vez sobre los múltiples puertos y caletas por los que enemigos y piratas entran a robar ganado y bienes, por lo que se vuelven a demandar medios al rey.

Según lo que se recoge en las actas correspondientes a las fechas señaladas, el 26 de junio de 1547, una nao inglesa, y en los días previos, una francesa, ambas artilladas, fondean en el puerto, robando, al menos la francesa, algunos navíos allí

${ }^{16}$ Este terraplén, que no sabemos si se desmonta en un futuro previo a la edificación de la fortaleza, puede ser la estructura anexa al sur de los restos de la traza de dicha fortaleza, dibujada en el plano de Torriani, perpendicularmente al muelle que se construiría posteriormente (1549), y que daría cobertura al fondeadero del lugar.

${ }_{17}$ Catálogo del Archivo Municipal de La Laguna, p. 142: Fondo Antiguo, Sección I, Libros Capitulares, Oficio Primero, número 6.

${ }_{18}$ Aunque hemos de recordar que la patente de corso, fórmula contractual para ejercer la piratería, respaldada por una nación, hacia navíos o enclaves de reinos enemigos, no se formalizó hasta el siglo XviII. Aun así, el término se utilizaba para el mismo tipo de piratería, aunque no existiese aún ese modelo contractual. 
anclados $^{19}$. Por ello, el 27 se da permiso para empezar a trazar la fortaleza, y Bartolomé Joven, personero, obtiene a su vez permiso para la venta de hasta 4000 ducados de madera y leña de propios, actividad que se debía registrar en forma de asiento, y así conseguir fondos para comprar munición y comenzar la obra.

En noviembre de ese año, en el Cabildo se vuelve a tratar sobre la torre y la traza de la fortaleza, y se reclama la presencia del maestre de la obra, Palacios, que en esos momentos está en Gran Canaria, para que certifique la correcta ubicación de la torre en el entorno del puerto ${ }^{20}$.

En enero de 1548, ya se está haciendo en Santa Cruz una torre y defensa, y se designa a Diego Díaz la supervisión de las obras. Pero en abril, sin cal para ésta, se encomienda a Pedro de Ponte concertar la compra de 200 cahíces de la misma ${ }^{21}$. Seguidamente, el 23 de abril, aparte de la falta de cal, se notifica que se tienen 400 sillares tallados en las canteras del valle de San Andrés a la espera de ser recogidos para la construcción, pero, por lo que deducimos, parece no haber una infraestructura administrativa lo suficientemente firme para coordinar todo. Estos sillares o cantos parece ser que esperaron más de un año para ser llevados a Santa Cruz.

En esta serie de acontecimientos, vislumbramos que la dificultad para transportar los sillares es decisiva para la construcción del muelle -infraestructura idónea para un puerto-, y se acuerda su construcción. La primera actividad que se mandaría a hacer una vez terminado, tal y como veremos a continuación, será desembarcar por él los sillares para la torre, que entendemos que es el futuro cubelo sur de la fortaleza, colindante al embarcadero, y que parece que quedó poco más que proyectada. El proceder es el que sigue:

El 11 de febrero de 1549, se manda buscar y adquirir barbusano o tea, aunque sea por mar desde Taganana. Debía ser barbusano consistente, o de tea pura y fina -entendemos que compacta, sin veteado quebradizo-. Se habría de hacer una vitola -armazón- para trazar el muelle, y llevaría argollas de latón, aunque no se especifica si su función es la del amarre de embarcaciones o el fijado de la estructura. Por el contexto, deducimos lo segundo.

El 13 de mayo, se encomienda a los regidores la supervisión de las obras, y que se compruebe cuánta cal y medios de más se necesitan. El último día de mayo, se manda acabar las obras del muelle, por lo que sabemos que la construcción, nunca mejor dicho, estaba llegando a buen puerto.

En junio, se sigue buscando dinero para rematar la obra, y en septiembre, se pide informe al maestre de cantería Francisco Merino para ver cuánta piedra del valle de Salazar se necesitará para terminarla. De esta forma, se mandan dos cabuqueros-canteros- para extraerla. En ese mismo mes de septiembre, las actas del día

19 Y por lo que se cita, esto ocurría a menudo.

${ }^{20}$ Hemos de precisar que, en los textos, se utilizan los términos torre y fortaleza indistintamente.

${ }^{21}$ Para hacernos una idea de las dimensiones de la obra, hablamos de un volumen aproximado de 130000 litros y una masa aproximada de 430000 kilos para el caso de la cal. 
24 recogen que se ha hecho y hace un muelle de cantería para abrigar dicho puerto ${ }^{22}$. En la misma entrada, se explica que, hasta la llegada del nuevo gobernador, el 15 de junio de 1548, el licenciado Juan Baptista de Ayora, no se había edificado ningún muelle, por lo que, aunque la caleta del barranquillo del Aceite era el embarcadero natural, no hubo infraestructura de muelle hasta esta fecha.

El 29 de noviembre de 1549, se encomienda a los regidores la visita al nuevo muelle de Santa Cruz, y que se desembarquen por él los cantos -sillería- para la obra, que esperaban en el valle de Salazar. El muelle estaba terminado ${ }^{23}$.

Es en 1553 cuando se decide definitivamente construir una fortaleza en condiciones. Los acontecimientos decisivos serían el ataque de Antoine Alphonse de Saintonge a Santa Cruz en 1552 y el ataque de François Le Clerc -Pata de Palo-a Santa Cruz de La Palma en 1553, hechos que alarmaron a la población y a los cabildos.

Parece ser, por los documentos consultados, que la torre no llegó a concluirse, puesto que en las disposiciones para construir la fortaleza y en otros documentos, expedientes de compraventa de propiedades -expropiaciones- para dejar espacio para su construcción, no se menciona; pero se sabe que el baluarte siguió en funcionamiento ${ }^{24}$.

Tal y como se podrá ver en las transcripciones citadas ${ }^{25}$, el lugar y puerto disponía de varios almacenes cerca del embarcadero y de la plataforma que daba cobertura a dicho muelle, que entendemos que era el baluarte. Para dejar espacio para la nueva construcción, el Cabildo debía comprar algunas propiedades cercanas al baluarte, bien para derribarlas o bien para aprovecharlas. La traza del nuevo baluarte o fortaleza -en la que incluimos su terraplén, elevado, y su espacio trasero amurallado- debía hacerse desde el frente oriental de la laja -la mencionada colada basáltica-, hasta la calle que va a dar a la ermita de Nuestra Señora de la Consolación -que ubicamos en la proximidad del muy futuro edificio de la Aduana-. Desde ese lugar, en el límite norte de la traza urbana, el muro perimetral occidental, del que sería el espacio trasero de la fortaleza, colindaría con la calle Real ${ }^{26}$, que se quedaría al oeste del mismo, hasta llegar al solar que Diego Díaz tenía a tributo del monasterio del Espíritu Santo, discurriendo en sentido sur de la calle, dejando cua-

\footnotetext{
${ }^{22}$ De esto hablaremos más adelante, junto a una referencia del protocolo notarial de Francisco de Zambrana.

${ }^{23}$ Desarrollaremos en la segunda parte del artículo más aspectos e información sobre el muelle, reparos y lo acontecido en su entorno próximo.

${ }^{24}$ La información detallada de los porvenires y detalles de las obras se muestra en las transcripciones sobre los documentos relativos a la fortaleza de Santa Cruz de Tenerife, publicados también en este número de la Revista de Historia Canaria.

${ }^{25}$ Folio 5 vuelto del documento transcrito número 1, titulado Sobre la necesidad de construir una Fortaleza en Santa Cruz.

${ }^{26}$ La denominación calle Real se recibe del tramo de un camino real a su paso por un núcleo urbano. Su denominación se encuentra, entre otras, en la página 367 Recto del protocolo notarial de Francisco de Zambrana, numeración procedente de la digitalización del Archivo Histórico Provincial de Santa Cruz de Tenerife. Por el mismo protocolo, sabemos que el 31 de marzo de 1568, el escribano Francisco Márquez tiene una bodega colindante con la ermita.
} 
tro metros de espacio para el paso. Desde allí, la traza debía cerrarse volviendo al este, hacia la mar, incorporando parte del terraplén del baluarte existente, la plataforma del muelle. La superficie delimitada por el perímetro incluiría las casas y propiedades de diversos vecinos. Aun así, se acordó que se extendiera la plaza -espacio a fortificarse- unos 25 pies más, tomando parte del almacén de Juan Pacheco y de la parcela de Diego Díaz, para así encuadrar la traza de la futura fortificación. Nos ubicamos el 2 de agosto de 1553 .

El 28 de agosto, la traza ya está definida y la obra se ha comenzado. Dos semanas después la plaza defensiva solo quedaba por rematarse. Se acordó entonces edificar la fortaleza, para lo que el regimiento decidió reunirse en el lugar, y así ver cómo se haría.

Al finalizar octubre, el regidor Juan de Meneses, en una nueva reunión del Concejo, dictamina que se construya una torre para defender el puerto -si bien no sabemos qué pasó finalmente con la propuesta de 1548-. Se necesita cal, y se autoriza al mayordomo del Cabildo para que la pague de propios. Se le manda que compre cal en piedra en Gran Canaria y que la cargue en cinco o seis navíos, de lo que extrapolamos que la cantidad de cal oscilaría entre 600 y 1200 toneladas aproximadamente, si nos ceńimos a la capacidad de arqueo de los carabelones de la época, aunque éste es un cálculo estimativo y con un amplio margen. A principios de noviembre, se da poder a Juan de Fiesco, regidor, para concertar con los cabuqueros que piquen y labren toda la cantería necesaria, que se habrá de pagar en las cantidades y plazos estipulados. Se le da poder completo para resolver los problemas o conflictos que de las diligencias pudieren surgir. A principios de diciembre, la torre ya se había empezado a trazar.

La primera propuesta para emplazar la torre era, dentro del perímetro marcado, el entorno más próximo a la ermita de la Consolación. El edificio de planta cuadra de la fortaleza se ubicaría en la parte oriental de la plaza que hacía de nuevo baluarte, junto y de cara al mar. Se estiman unas medidas, que no serían las definitiva $^{27}$, y se propone en varias ocasiones que se haga un cubelo - una torre- en la esquina norte, el entorno ya mencionado, y otro al sur, junto al embarcadero. Además, se manda acordar con Sancho de Salazar que se quite una casa que tiene en las proximidades de la futura torre norte. Respecto al edificio principal, se propone un edificio de cantería fuerte a tres alturas, con tres andanas y espacio a tres alturas para artillería, pero el porvenir sería diferente.

Las siguientes menciones de la fortaleza que analizamos son ya de 1557. Citan, en la descripción bajo juramento que hace Francisco Merino, maestre de cantería, que el terraplén hecho tiene un frente -en el eje norte-sur- de 60 metros, un ancho -de este a oeste- de 10 metros y una altura de 6,3 metros de la banda del mar-que rompía junto al muro-, y, adaptándose a la orografía inclinada, 4,2 metros de la

27 Véanse las transcripciones mencionadas. Para este caso, véase 'Sobre la Necesidad de Construir una Fortaleza en Santa Cruz', folios 15 recto en adelante. En esta misma línea, la información que será presentada aquí proviene de esos textos. 
banda de tierra. Finalmente, este terraplén relleno de tierra y escombros sustituía al baluarte a tres alturas propuesto ańos antes. Estaba parapetado por un ancho muro de cantería fuerte, que se estrechaba en función de su altura en la banda del mar, pasando a ser de argamasa y mampuestos a partir de la mitad de su altura, siendo rematado por una última hilada y almenas también de cantería. El muro del terraplén -que no el del conjunto- de la banda del lugar era también de mampostería ${ }^{28}$.

El cubelo sur, próximo al embarcadero, estaba inconcluso, no pasaba en 1557 casi de los cuatro metros de altura. Se estaba construyendo su entrada, con una recia puerta de madera y una reja de hierro, que se habría de alzar por torno. El interior estaba apisonado y tenía un patio de casi diez metros de diámetro.

El cubelo norte está finalizado. Estaba hecho de cantería, cal y mampuestos, y contaba con troneras de cantería.

Entre otras diligencias, se platica sobre si se ha de trasladar la ermita de la Consolación, ya que, si ésta fuere capturada, se podría ejercer un dominio de fuego sobre el terraplén, ya que lo superaba en altura. Se propone la idea de subir el muro de la banda de tierra, y ensanchar el terraplén cuatro metros hacia el oeste para el mejor tránsito de la artillería, así como ensanchar una sección del mismo hacia la caletilla del norte -al pie del cubelo-, haciendo este ensanche de más altura, dando cobertura a la caleta de Blas Díaz y al terraplén existente, más bajo. Pero mover el cubelo norte sería obra difícil, y el cubelo sur, sin terminar, perdería su función, ya que el terraplén propuesto sería de la altura de las mencionadas torres -una vez se terminase la de la esquina sur-. Sobre este terraplén nuevo se debería hacer un almacén de municiones y pertrechos. A su vez, se indica que el aposento del alcaide debería moverse junto al lienzo -muro- y entrada de la fortaleza. Este terraplén no llegó a materializarse, ya que en noviembre de 1566 se vuelve a platicar sobre su construcción y sobre ensancharlo hacia la caletilla, además de sumarle un caballero $^{29}$, una doble altura para protegerlo, quedando el terraplén 'aterrazado' y señoreado por esta adición.

En 1558, la Corona envía a Alonso Pacheco, criado, para que haga una relación sobre las fortificaciones y hombres de armas que hay en Canarias. En febrero de 1559, acompañado de la Real Cédula que lo ordena, llega a Tenerife. En su visita al puerto de Santa Cruz, recoge la descripción y medidas de la fortaleza, entre las que destaca el fin del cubelo sur, y que éste, en su patio interior, tiene un pozo excavado y cubierto de ladrillo, de diez metros de profundidad. Ambos cubelos medían diez metros y medio de altura, y, al menos el del norte, tenía dos alturas, y una tercera techada y almenada. Es de suponer que el del sur se remataría de la misma forma. Ambos estaban anexos al terraplén. La entrada a dicha plataforma contaba con una escalera levadiza, puerta de madera guarnecida de hierro y una reja de hierro que se alzaba a torno. Sobre ésta, el escudo de armas reales de la Isla. Entendemos que ésta está en la cara sur del recinto.

28 Lógico, ya que no sufriría impactos de artillería y abarataba costes.

29 Espacio más alto de una fortificación para dar cobertura. 

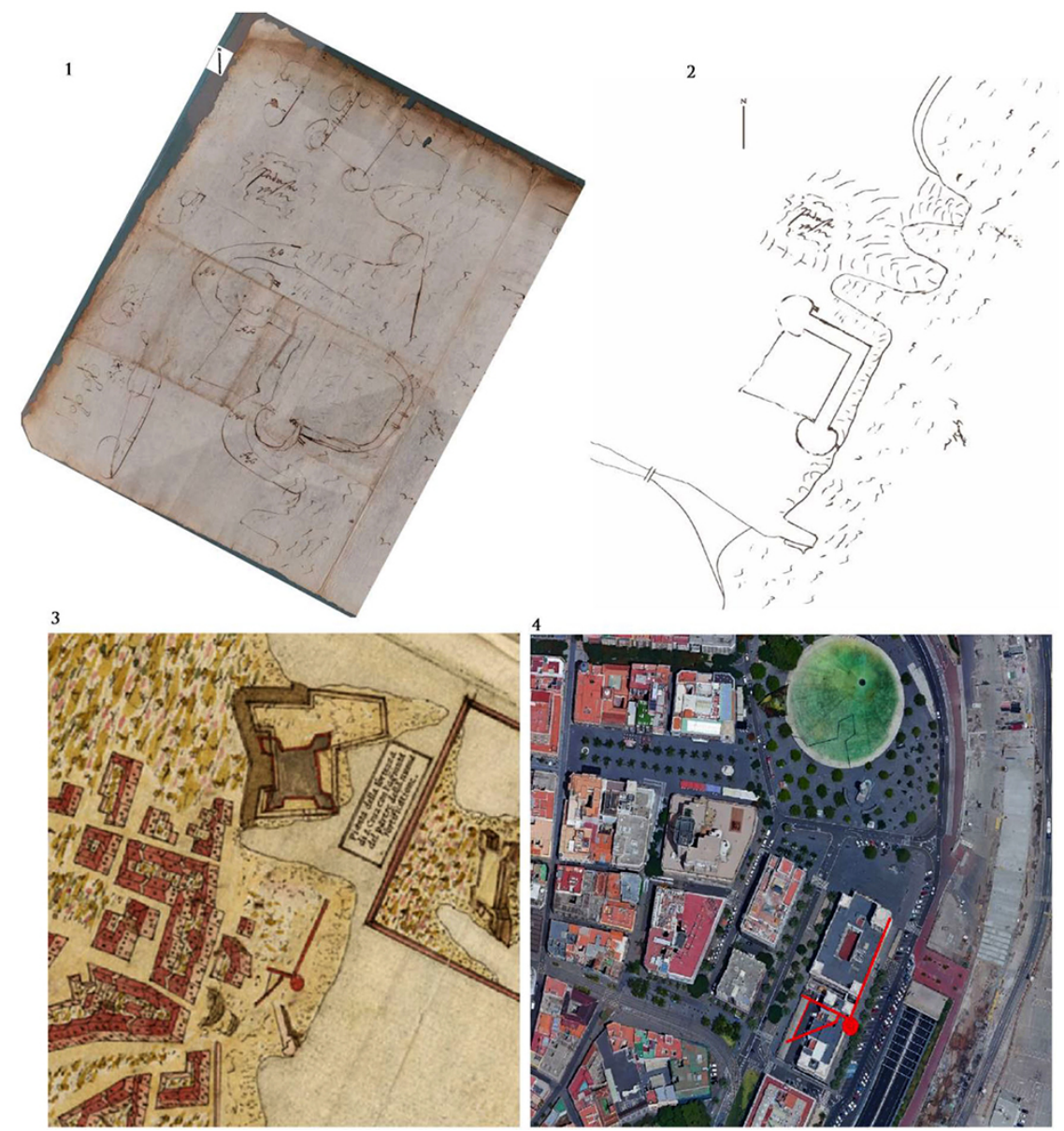

Figura 4. 1. Boceto sobre la propuesta de Juan Sánchez de Zambrana, con indicación del norte geográfico. Se pueden observar las trazas que prolongó hacia el norte desde la plataforma que proponía construir para dar cobertura a los abrigos y caletas. Se aprecia el fondeadero en aquel entonces, señalado como 'Surgidero'. 2. Modificación del boceto, en el que se muestra limpiamente

la traza aproximada a la original, destacando que los muros en escuadra corresponden a los cimientos de cantería del terraplén, sin estar éste indicado. Al norte, otra colada basáltica que se adentraba en el mar -hoy bajo la plaza de España-, y al sur, la caleta del barranquillo del Aceite, que interpretamos como la caleta de Blas Díaz. Entre ésta y el cubelo sur, el embarcadero.

3. Traza parcial del plano de la fortaleza en el plano de Leonardo Torriani.

4. Relación de dicha traza parcial sobre una imagen de satélite actual (Google Earth).

Entre las diligencias encomendadas por el criado real, el muro perimetral de la banda de tierra habría de ser de la misma longitud que el terraplén, y se propone hacer otro cubelo junto al cubelo norte, al oeste del mismo. Propone ensanchar el terraplén para que juegue la artillería con facilidad, tal y como se proponía 
desde hacía tiempo, y construir los aposentos del alcaide junto a éste, de la banda del sur. A su vez, recomienda duplicar la altura de los cubelos y quitar las casas más próximas, al sur, al norte, y trasladar la ermita de lugar.

Parece que mucho no se cambió en la fortaleza una vez que comenzó a usarse. La siguiente referencia consultada es la propuesta que hace en 1568 el alcaide Juan Sánchez de Zambrana, de desmontar el terraplén, manteniendo los muros de contención y parapeto, a la vez que se extendería el terraplén hacia el mar, sobre la laja -la colada basáltica sobre la que se asentaba la fortaleza y se adentraba en el agua-, para dar cobertura de artillería a los abrigos y caletas inmediatamente al norte. También proponía un foso desde la caletilla bajo el cubelo norte hasta el embarcadero. No parece que se llevase a cabo su proyecto.

Del muelle, que estaría junto al cubelo sur y se adentraba en el mar sobre protuberancias de la colada basáltica, veremos más indicaciones en la segunda parte del artículo. Éste cerraba el entorno de la caleta -tal y como señalamos en la nota 22-, a espaldas de la fortaleza ${ }^{30}$ y en sus proximidades fondeaban los navíos ${ }^{31}$.

ReCiBIDO: 11-5-2020; ACEPTADO: 11-6-2020

30 Imágenes 221 v-222 r, del protocolo notarial de Francisco de Zambrana, 13 de diciembre de 1568 .

31 Imágenes 251 r-255 r, de dicho protocolo, 2 de octubre de 1566. Se cita una barca -entendemos que una carabela, ya que se valora en 120000 maravedíes, sin contar barqueta ni ancla-, surta cerca del muelle, desde donde se puede oír y ver lo que en ella ocurre. 


\section{BIBLIOGRAFÍA}

Cioranescu, Alejandro (1993). Historia del Puerto de Santa Cruz de Tenerife, Canarias, Viceconsejería de Cultura y Deportes, Gobierno de Canarias.

Cioranescu, Alejandro (1998). Historia de Santa Cruz de Tenerife, vols. I-II, Ayuntamiento de Santa Cruz de Tenerife.

De Espinosa, Alonso (1594). Del Origen y Milagros de la Santíssima Imagen de Nuestra Señora de Candelaria, Imprenta de Juan de León, Sevilla, digitalizado por la Biblioteca del Congreso de Estados Unidos.

De la Rosa Olivera, Leopoldo (c. 1944). Catálogo del Archivo Municipal de La Laguna, originalmente en Revista de Historia Canaria, digitalizado por la Universidad de Las Palmas de Gran Canaria.

De la Rosa Olivera, Leopoldo y Marrero, Manuela (1986). Acuerdos del Cabildo de Tenerife v 15251533, serie Fontes Rerum Canariarum xxvi, La Laguna, Instituto de Estudios Canarios.

De la Rosa Olivera, Leopoldo y Serra Ràfols, Elías (1949). El Adelantado Don Alonso de Lugo y su Residencia por Lope de Sosa, serie Fontes Rerum Canariarum III, La Laguna, Instituto de Estudios Canarios.

García Montes de Oca, Alberto y Rodríguez Illescas, José Miguel (2018). El Protocolo Notarial de Francisco de Zambrana 1565-1569. Esta monografía fue financiada por la Dirección General de Patrimonio Cultural del Gobierno de Canarias y en la actualidad no se ha publicado.

Marrero, Manuela, Padrón, María y Rivero, Benedicta (1997). Acuerdos del Cabildo de Tenerife VI 1538-1544, serie Fontes Rerum Canariarum xxxvi, La Laguna, Instituto de Estudios Canarios.

Marrero, Manuela, Padrón, María y Rivero, Benedicta (2000). Acuerdos del Cabildo de Tenerife VII 1545-1549, serie Fontes Rerum Canariarum XxxviII, La Laguna, Instituto de Estudios Canarios.

Mederos Martín, Alfredo y Escribano Cobo, Gabriel (2018). «Evolución histórica del Puerto de Santa Cruz de Ańazo (Tenerife, Islas Canarias)». Anuario del Instituto de Estudios Canarios. Lx. Consultado en https://www.academia.edu/41917395/Evoluci\%C3\%B3n hist\%C3\%B3rica_del_Puerto_de_Santa_Cruz_de_A\%C3\%B1azo_Tenerife_Islas_Canarias_Historical_evolution_of_the_Port_of_Santa_Cruz_of_A\%C3\%B1azo_Tenerife_ Canary_Islands_.

Pinto y De la Rosa, José María (1996). Apuntes para la Historia de las Fortificaciones de Canarias, Santa Cruz de Tenerife, Instituto de Historia y Cultura Militar de Canarias.

Rumeu de Armas, Antonio (1947-1949). Canarias y el Atlántico. Piraterías y Ataques Navales contra las Islas Canarias, v tomos, Madrid, CSIC.

Serra Ràfols, Elías (1949). Acuerdos del Cabildo de Tenerife I 1497-1507, serie Fontes Rerum Canariarum IV, La Laguna, Instituto de Estudios Canarios.

Serra Ràfols, Elías y De la Rosa Olivera, Leopoldo (1952). Acuerdos del Cabildo de Tenerife II 1508-1513, serie Fontes Rerum Canariarum V, La Laguna, Instituto de Estudios Canarios.

Serra Ràfols, Elías y De la Rosa Olivera, Leopoldo (1965). Acuerdos del Cabildo de Tenerife iII 1518-1514, serie Fontes Rerum Canariarum XIII, La Laguna, Instituto de Estudios Canarios. 
Serra Ràfols, Elías y De la Rosa Olivera, Leopoldo (1970). Acuerdos del Cabildo de Tenerife IV 1518-1525, serie Fontes Rerum Canariarum Xvi, La Laguna, Instituto de Estudios Canarios.

Tous Meliá, Juan (2004). El Hércules. El Cañón más Precioso del Mundo. Una aproximación a la historia de Canarias a través de la Artillería, San Cristóbal de La Laguna, Juan Tous Meliá.

Artículos

Lobo Cabrera, Manuel (1987). «La población de Tenerife en el siglo Xvi», en Anuario de Estudios Atlánticos, n. ${ }^{\circ} 33$, pp. 379-416.

Marrero, Manuela (1977). «Algunas consideraciones sobre Tenerife en el primer tercio del siglo XVI», en Anuario de Estudios Atlánticos, n. ${ }^{\circ} 23$, pp. 373-382.

Millán de Silva, Patricia (2012). «Las Expediciones de Don Álvaro de Bazán, primer Marqués de Santa Cruz, a las Islas Canarias (1555-1559)», en Revista de Historia Naval, Número 119, pp. 69-90.

\section{ARCHIVOS}

Archivo Municipal de La Laguna, Fondo Antiguo, Sección Primera:

Caja F I: Fábricas Públicas.

Caja F IX: Fortificaciones.

Caja R VI: Reales Cédulas, Carpeta número 7.

Papeles sueltos de Juan de Azoca, 1533-1560.

Archivo Histórico Provincial de Santa Cruz de Tenerife:

Protocolo Notarial de Francisco de Zambrana, 1565-1569 (PN 1.221).

Universidad de Coimbra:

Torriani, L. (1590). Alla Maesta del Re Catolico, descrittione et historia del regno de l'isole Canarie gia dette le Fortunate con il parere delle loro fortificationi, copia digital, Universidad de Coimbra. 